\title{
Final Report: Contractor Readiness Assessment (CRA) for TREAT Fuel Movement and Control Rod Drives Isolation
}

\author{
Dave Rowsell
}

June 2015

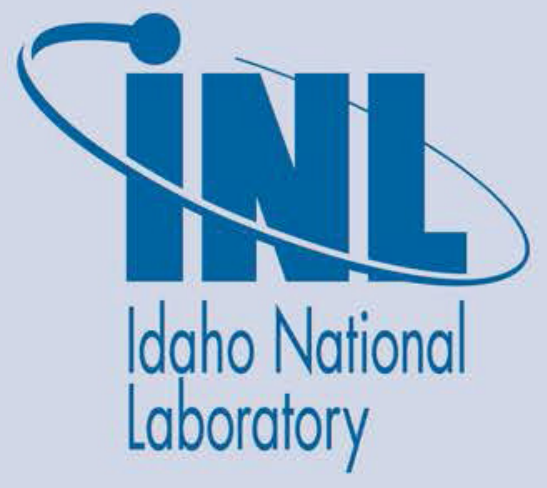

The INL is a U.S. Department of Energy National Laboratory operated by Battelle Energy Alliance 
INL/EXT-15-35507

\title{
Final Report: Contractor Readiness Assessment (CRA) for TREAT Fuel Movement and Control Rod Drives Isolation
}

\author{
Dave Rowsell \\ June 2015 \\ Idaho National Laboratory \\ Idaho Falls, Idaho 83415 \\ http://www.inl.gov \\ Prepared for the \\ U.S. Department of Energy \\ Under DOE Idaho Operations Office \\ Contract DE-AC07-05ID14517
}




\section{DISCLAIMER}

This information was prepared as an account of work sponsored by an agency of the U.S. Government. Neither the U.S. Government nor any agency thereof, nor any of their employees, makes any warranty, expressed or implied, or assumes any legal liability or responsibility for the accuracy, completeness, or usefulness, of any information, apparatus, product, or process disclosed, or represents that its use would not infringe privately owned rights. References herein to any specific commercial product, process, or service by trade name, trade mark, manufacturer, or otherwise, does not necessarily constitute or imply its endorsement, recommendation, or favoring by the U.S. Government or any agency thereof. The views and opinions of authors expressed herein do not necessarily state or reflect those of the U.S. Government or any agency thereof. 
Final Report: Contractor Readiness Assessment (CRA) for TREAT Fuel Movement and Control Rod Drives Isolation

\author{
June 4, 2015
}

Approved:
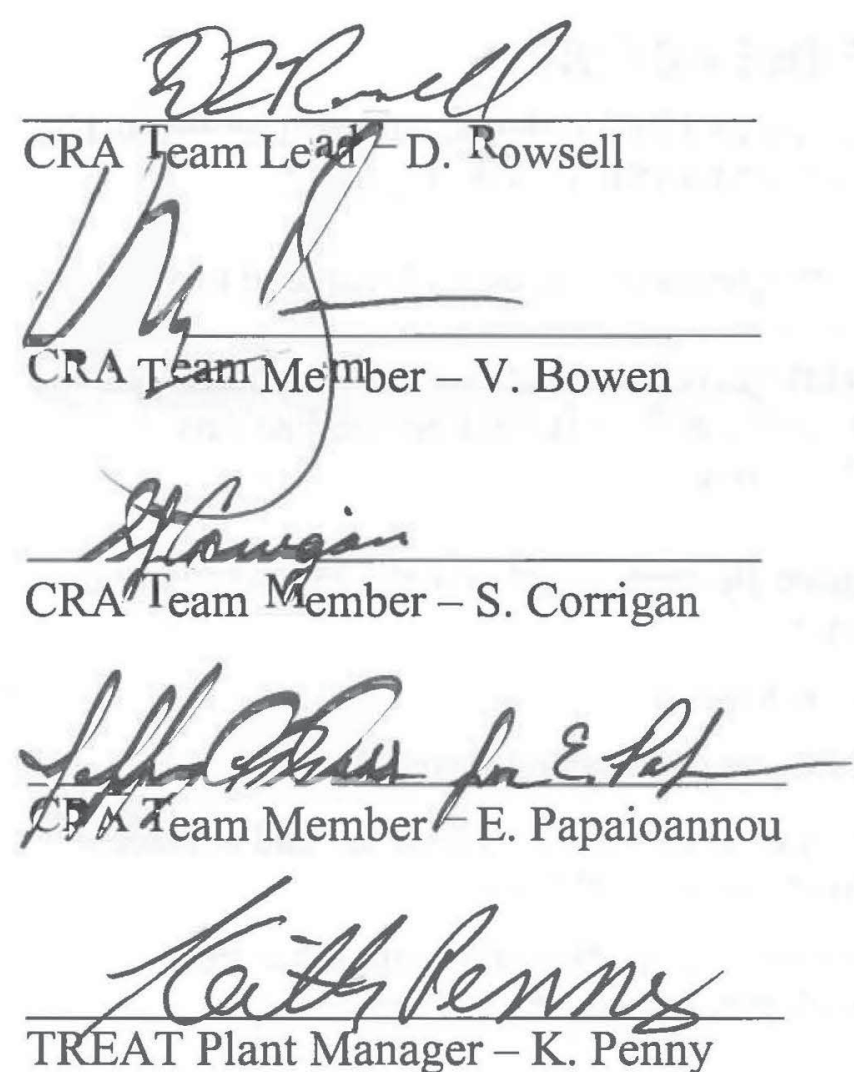
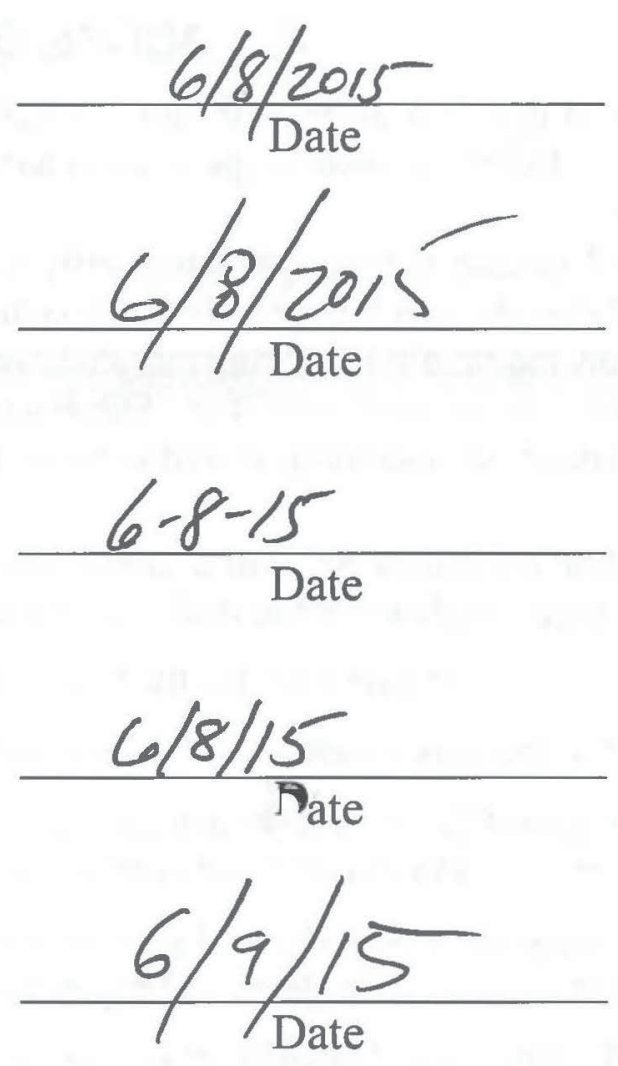


\section{Final Report: Contractor Readiness Assessment (CRA) for TREAT Fuel Movement and Control Rod Drives Isolation}

\section{INTRODUCTION}

This report documents the Contractor Readiness Assessment (CRA) for TREAT Fuel Movement and Control Rod Drives Isolation. The review followed the approved Plan of Action (POA) and Implementation Plan (IP) using the identified core requirements. The activity was a limited scope focusing on the control rod drives functional isolation and fuel element movement. The purpose of this review is to ensure the facility's readiness to move fuel elements thus supporting inspection and to functionally isolate the control rod drives to maintain the required shutdown margin.

\section{SCOPE OF THE ACTIVITY}

The scope of the CRA includes the nuclear safety related TREAT shutdown activities directed by the DOE-ID to be reviewed as specified in letter AS-CMD-INL-15-038. These are:

- TREAT nuclear fuel movement-specific activity operations and controls required to avoid a drop that could result in breached fuel element clad.

- Controls required for ensuring that shutdown margin requirements are met for control rod movement or removal activities. Subsequent control rods or control rod mechanisms maintenance or operations activities were not in scope.

A demonstration of movement of a stored non-fueled element assembly in the TREAT storage areas was performed during the readiness assessment.

The selected core requirements for the review are as follows:

CR \#2 Functions, assignments, responsibilities, and reporting relationships

- Criterion 2.1 - A clear management structure is established, approved, and in place to support fuel movement and control rod drive isolation activities.

- Criterion 2.2 - Roles and responsibilities for TREAT Operations are delineated, understood, and implemented by applicable operations and support personnel.

CR \#3 Training and Qualification Programs

- Criterion 3.1 - Employee training plans adequately address nuclear safety aspects of fuel movement and control rod drive isolation activities. The training plans meet the requirements of PDD-147, Manual 12, and PLN-4826, RTTP Training Plan.

- Criterion 3.2 - Operations and operations support personnel are trained and qualified/certified for fuel movement and control rod drive isolation activities and training has been conducted for current revisions of the operations procedures that 
address these activities. Training addresses facility modifications for the fuel handling tool(s).

- Criterion 3.3 - Positions requiring certifications are identified and required documentation is complete and current.

- Criterion 3.4 - Training and qualifications are appropriate for the range of duties and activities to be performed.

- Criterion 3.5 - Training records are current.

CR \#4 Level of Knowledge

- Criterion 4.1 - Operations, management, and support personnel demonstrate adequate knowledge of fuel movement and control rod drive isolation activities, Safety Basis requirements and controls, procedures, and operations in the breadth and depth appropriate for their assigned roles and responsibilities.

- Criterion 4.2 - Operations and operations support personnel demonstrate the ability to carry out fuel movement and control rod drive isolation procedures.

CR \#8 Facility Modifications

- Criterion 8.1-Modification Engineering Jobs (EJs) and the activity description in S3942-0001-YT are consistent and as analyzed in the DSA.

- Criterion 8.2 - Work orders supporting and/or associated with the fuel handing tool modifications have been properly completed, recorded, tracked, and closed.

- Criterion 8.3 - The required drawings and design output documents for the fuel handling tool(s) have been identified for configuration control and have been verified accurate with the field installation.

CR \#9 Procedures and Safety Limits

- Criterion 9.1 - Procedures related to fuel movement and control rod drive isolation have been approved and are available to the operators to enable them to monitor and control operation under normal, abnormal, and emergency conditions.

- Criterion 9.2 - Fuel movement and control rod drive isolation procedures implement applicable safety requirements for operation as delineated in the DSA and TS. Procedures for fuel movement and control rod drive isolation activities are consistent with the configuration described in S3942-0001-YT and Z0003-0005-OS.

CR \#12 Conduct of Operations

- Criterion 12.1 - Personnel have demonstrated successful operations, and verifications of Conduct of Operations for fuel movement and control rod drive isolation. Operations procedures implement the principles of Conduct of Operations good practices. Conduct of operations is implemented in accordance with the Conduct of Operations conformance matrices and procedures. 
INL/EXT-15-35507

June 4, 2015

- Criterion 12.2 - Sufficient numbers of qualified personnel are available to conduct fuel movement and control rod drive isolation activities.

\section{CRA RESULTS}

The Plan of Action/Implementation Plan was followed. The movement of a dummy fuel element was observed, the strategy for the isolation of the control rods was presented by facility operations, the facility's evidence binder and other documentation was reviewed and personnel were interviewed by the CRA Team.

All personnel associated with the TREAT Project demonstrated that they understood and demonstrated great knowledge of the fuel movement and control rod drive isolation activities (see Noteworthy Practice NWP 4.1). They understood their individual roles and responsibilities. They demonstrated great teamwork and focus on the activities. Through the observed evolution operations and support personnel demonstrated the ability and expertise to carry out fuel movement. The briefing for the fuel transfer operation was conducted in an exemplary manner. The TREAT FAS demonstrated clear command and control, and utilized his personnel via a very well done reverse briefing technique. Operator and HPT knowledge of the procedure and operation itself were evident through their engagement in the briefing. Roles, process flow, "what - if" discussion, critical points, and abnormal and emergency operations were clear. (see Noteworthy Practice NWP 4.2).

The TREAT Project staff impressed the review team. They have developed a teamwork atmosphere and cohesiveness that is outstanding (see Noteworthy Practice NWP 4.3). The review team was also impressed by the TREAT Engineering management and staff. Their knowledge of the INL Conduct of Engineering process was outstanding (see Noteworthy Practice NWP 8.1). The TREAT Maintenance management also had an exemplary level of knowledge of Configuration Management and the Conduct of Engineering processes (see Noteworthy Practice NWP 8.2).

At the time of this review, a procedure had not been developed for control rod drive isolation. However, the facility has mapped and documented the strategy (and specific steps) for control rod drive isolation in a timely order (Operations Timely Order 15-03). This Timely Order has been used to inform all affected personnel of the method by which rod drive isolation will be conducted. Facility personnel intend to develop a work package(s) to perform the control rod drive isolation sequences necessary to accomplish rod drive inspection and testing. Utilization of Work Control (LWP-6200) for this process will ensure that adequate protection of the assumptions and controls established via TEV-2448 "Shutdown Margin Evaluation for Core Load 1469" are appropriately reviewed and approved. Without this procedure being in place core requirements \#3, \#4, and \#9 could not be fully verified. Pre-Start Finding 9.1 documents that there is no implementing procedure for control rod drive isolation. This also resulted in PreStart Finding 3.1 which documents that training and qualification for control rod drive isolation activities has not been conducted. Verification of Core Requirement \#4 specifically Criterion 4.2 could also not be completed as it requires procedures to be in place. The resolution of Core Requirement \#4 is covered by Pre-Start Finding 9.1. 
For fuel movement controlled by TREAT-OI-0301 it was noted that operators, FAS, supporting personnel, and management have an exemplary level of knowledge associated with fuel movement operations and associated Technical Specifications (TS). However, the barriers designed to ensure TS verification/validation occur at the appropriate procedural juncture specified in SP-50.0.2 were not present in the procedure or the associated implementing forms. Specifically, HPI barriers of bolded TS reference occurring before TS implementing steps and/or signature verifications called out for TS are not indicated in the procedure or on any of the implementing forms. An example of this omission is the lack of clear validation that Surveillance Requirement 5.2.2 requiring the TREAT Area Supervisor to verify that shutdown margin is met via all of the requirements listed in Section 6.0 of the Shutdown Letter prior to fuel handling in the core. Pre-Start Finding 9.2 documents that implementation of Technical Specifications in TREAT-OI-0301 and TREAT-OI-2050 do not comply with the requirements of TREAT SP-50.0.2.

During review of the Shutdown Margin Evaluation (TEV-2448) and the timely order (Operations Timely Order 15-03) it was discovered that the Conduct of Engineering Process was not used to document the removal of the PPS cables that isolate the control rod drives. The review team concluded that based on requirements in MCP-3955, "Conduct of Operations for the Transient Reactor Test (TREAT) Facility", step 4.8.8 "Control of Temporary Equipment Modifications and Temporary Systems", the Conduct of Engineering Process should have been followed. MCP-3955 states all modifications, whether permanent or temporary, will be controlled using INL engineering process. Pre-Start Finding 8.1 documents that Conduct of Engineering Process should have been used to document the removal of the PPS cables to isolate the control rod drives.

Criterion 2.1 asks for verification that a clear management structure is in place to support fuel movement and control rod drive isolation activities. As the Technical Specifications were reviewed the team became concerned about specific titles/positions and the associated requirements for those titles that are delineated in the document. Examples of this are as follows:

- Surveillance Requirement 5.2.2 - requires the "TREAT Area Supervisor" shall determine that the required shutdown margin is maintained at all times.

- Surveillance Requirement 5.2.3 - the "TREAT Area Supervisor" shall evaluate the reactivity data applicable to a core configuration, prior to authorizing a change in reactor loading ...

- Administrative Controls 6.2.3.11 - Keys to the scram-latch power circuit, which must be closed before reactor operation is possible, shall be held by the "TREAT Reactor Manager".

- Administrative Controls 6.2.3.14 - Qualification/certification of operating personnel shall be subject to approval by the "TREAT Facility Manager" or Laboratory and Hot Cell Services Department Manager. 
The Technical Specifications in the case of the "TREAT Area Supervisor" require specific qualifications for that position. The review team feels that this situation can become a trap that may end up in a violation of the Technical Specifications. Where these titles/positions are contained (and in one case defined) within the Technical Specifications it appears that fuel element inspection and control rod isolation with subsequent testing cannot be completed without personnel in place who hold these titles/positions. Pre-Start Finding 2.1 documents that titles/positions as currently defined by the TREAT Project are not consistent with titles and/or positions identified in the Technical Specifications.

Related to the discussion on Criterion 2.1, it should be noted that the observed evolution consisted of ex-core retrieval and movement of a "dummy" fuel element from Zone 1 in MFC720. Currently, an evolution for in-core movement would not have the required training complete nor qualified personnel ready to support. The modifications to PDD-147 to identify the certified positions of shutdown reactor operator (SDRO), shut down shift supervisor (SDSS) and TREAT Area Supervisor are not complete. PLN-2846 identified the SDRO and SDSS. However, that document points back to PDD-147 for implementation of the DOE Order requirements. Further action will be necessary to ensure these positions are identified and documented in the TREAT training program documentation.

Eight (8) observations are documented in this review. The observations can be summed up into two categories. First, suggestions to enhance procedures. Second, suggestions to further improve the existing solid conduct of operations approach.

In total the review team identified five (5) Pre-start findings, eight (8) observations and five (5) noteworthy practices.

\section{Findings:}

Pre-Start 2.1: Titles/Positions as currently defined by the TREAT Project are not consistent with titles and/or positions identified in the Technical Specifications. (Reference: Verification of Core Requirement \#2, Criterion 2.1 - A clear management structure is established, approved, and in place to support fuel movement and control rod drive isolation activities). [CO 20152472]

Pre-Start 3.1: Training and qualification for control rod drive isolation activities has not been conducted. (Reference: Verification of Core Requirement \#3, Criterion 3.2 - Operations and operations support personnel are trained and qualified/certified for fuel movement and control rod drive isolation activities and training has been conducted for current revisions of the operations procedures that address these activities). [CO 2015-2473] 
Pre-Start 8.1: Conduct of Engineering Process should have been used to document the removal of the PPS cables to isolate the control rod drives. The PPS Cables (J7, J8, J9) that were removed to isolate control rod drives did not have any engineering involvement prior to removal. (Reference: MCP-3955, “Conduct of Operations for the Transient Reactor Test (TREAT) Facility") [CO 2015-2474]

Pre-Start 9.1: There is no implementing procedure for control rod drive isolation. (Reference: Verification of Core Requirement \#9, Criterion 9.1 - Procedures related to fuel movement and control rod drive isolation have been approved and are available to the operators to enable them to monitor and control operation under normal, abnormal, and emergency conditions). [CO 2015-2475]

Pre-Start 9.2: Implementation of Technical Specifications in TREAT-OI-0301 and TREAT-OI2050 do not comply with the requirements of SP-50.0.2. (Reference: TREAT SP-50.0.2) [CO 2015-2476]

\section{Noteworthy Practices:}

NWP 4.1: TREAT Operations, Management and support personnel have an exemplary level of knowledge associated with the fuel movement and control rod drive isolation activities. They understood the procedures, controls, requirements and necessary operations in great detail as appropriate for their assigned roles and responsibilities. [CO 2015-2477]

NWP 4.2: The briefing for the fuel transfer operation was conducted in an exemplary manner. The TREAT FAS demonstrated clear command and control, and utilized his personnel via a very well done reverse briefing technique. Operator and HPT knowledge of the procedure and operation itself were evident through their engagement in the briefing. Roles, process flow, "what - if" discussion, critical points, and abnormal and emergency operations were clear. [CO 2015-2478]

NWP 4.3: The TREAT Project staff has developed a teamwork atmosphere that stands out. This team concept and cohesiveness will be a great asset in driving this project to success. (CO 2015-2479]

NWP 8.1: During interviews with the TREAT Engineering Manager and TREAT Fuel Handling Tool System Engineer, the assessor was very impressed with their knowledge of the INL Conduct of Engineering process. The following noteworthy practices are very well understood and implemented when requested to perform engineering activities [CO 2015-2480]:

- Developing engineering inputs up front in accordance with LWP-10000

- Approving engineering inputs per LWP-10000

- Determining when Engineering Change Control required

- When to proceed with developing engineering deliverables

- How the determine level of verification for engineering deliverables 
- Performance of EJ verification and the proper selection for verification

- Facility modifications will not be performed prior to verification of EJ

- Revision of documents affected by facility modification, prior to EJ closeout

- Proper understanding of EJ Turnover and EJ Closeout

- Proper use of Engineering Drawing Change Log

- Maintaining Configuration Management of Structures, Systems and Components

NWP 8.2: During interviews with the TREAT Maintenance Manager and TREAT Implementation Manager it was noted that these individuals had an excellent understanding of not approving work packages that will modify the facility or install a new SSC, until the EJ has been verified (LWP-6200, step 4.11.2). [CO 2015-2481]

\section{Observations:}

Observation 9.1: TREAT-OI-2050 implements TS, but is not needed to be in hand for crane use potentially resulting in missing TS verification. [CO 2015-2482]

Observation 9.2: Section 5.0 of ALARA review (TREAT-2015-001) contains a monitoring requirement that is not implemented in procedure. [CO 2015-2483]

Observation 9.3: LST-320, TREAT Nuclear Safety Implementation Matrix has not been maintained current. [CO 2015-2484]

Observation 9.4: The fuel handling procedure controls highly consequential operations and is Use Type 2. [CO 2015-2485]

Observation 9.5: FRM-1738, “Transient Reactor Test Facility (TREAT) Fuel Loading Chart" is not used/updated during in core fuel movements. [CO 2015-2486]

Observation 12.1: Prerequisites are not written in a clearly conditional manner (If, then) in TREAT-OI-0301 as expected per 4.16.5 of MCP-3955. [CO 2015-2487]

Observation 12.2: OSL beta windows were noted to be taped over when implementing FME controls. [CO 2015-2488]

Observation 12.3: Use of 3-way communication was not used when directing activities or communicating critical information. [CO 2015-2489]

\section{CONCLUSION AND RECOMMENDATION}

Based on the results of the review, the CRA team concludes that following satisfactory completion and closure of the identified Pre-start findings all identified criterion within the core requirements will be met. After closeout of the Pre-start findings the CRA Team recommends 
control rod drive isolation and fuel element movement activities as defined with the reviewed scope may commence. The BEA CRA Team expresses our thanks to the DOE-ID RA Team for their participation, comments and assistance as we teamed together to complete this review.

Note: The BEA CRA Team Lead and the DOE-ID RA Team Lead are required to accept the resolution and closeout of the Pre-start findings.

\section{LESSONS LEARNED}

1. Placing the contents of the evidence binders into a shared folder was a great idea. It gave the review team easy access to the information from any work location.

2. The review team was impressed with the implementation and use of the TREAT Operations Review Committee (TORC). The use of this committee has added great value in making critical decisions that affect the TREAT restart effort.

\section{TEAM MEMBERS}

\begin{tabular}{|l|l|}
\hline \multicolumn{1}{|c|}{ Team Member } & \multicolumn{1}{c|}{ Core Requirements Reviewed } \\
\hline David Rowsell & $\begin{array}{l}\text { Team Lead; CR \#2 Functions, assignments, responsibilities, and } \\
\text { reporting relationships; CR \#4 Level of Knowledge }\end{array}$ \\
\hline Vince Bowen & $\begin{array}{l}\text { CR \#3 Training and Qualification Programs; CR \#4 Level of } \\
\text { Knowledge }\end{array}$ \\
\hline Shannon Corrigan & CR \#8 Facility Modifications; CR \#4 Level of Knowledge \\
\hline Eric Papaioannou & $\begin{array}{l}\text { CR \#9 Procedures and Safety Limits; CR \#12 Conduct of Operations; } \\
\text { CR \#4 Level of Knowledge }\end{array}$ \\
\hline
\end{tabular}

\subsection{David Rowsell Bio}

Mr. Rowsell is the Facility Engineering Manager for the INL Materials and Fuels Complex which includes 13 hazard category 2 and 3 nuclear facilities. He has over 28 years of experience in engineering and 24 years in engineering and operations of nuclear facilities. Mr. Rowsell has been in various engineering management positions for the last 12 years.

In his current role as MFC Facility Engineering Manager, he is responsible for:

- Facility operation support

- Requirements definition

- Design control

- Configuration management

- Facility modifications 
His experience includes:

- Department Manager, MFC Nuclear Operations Engineering

- Deputy Department Manager, ATR Engineering

- System Engineering Manager, ATR Engineering

- Project Engineer/Project Manager, ATR Life Extension Program

- Plant Engineering Manager, ATR Engineering

- Cognizant System Engineer

- Design Engineer

His experience with significant projects includes:

- Advanced Test Reactor Design Basis Reconstitution Program, ATR Life Extension Program, Project Manager

- ATR EFIS Flow Analysis Project, ATR Engineering, Analyst/Engineering Manager

- Demineralized Water Supply System Upgrade, ATR Engineering, Project Engineer

- Raw Water Storage Tanks Replacement Project, ATR Engineering, Project Engineer

- Secondary Coolant System Acid Storage Tank Upgrade, ATR Engineering, Project Manager

Over the past two years, Mr. Rowsell has led three Contractor Readiness Assessments (CRAs) and two Management Self Assessments (MSAs) and has served as a participant on several other assessments in support of MFC Facilities. He holds a Bachelor of Science degree in Mechanical Engineering from Utah State University.

\subsection{Vince Bowen Bio}

Mr. Bowen is the Materials and Fuels Complex Training, QA, and Performance Management Department Manager. Mr. Bowen has over 27 years of experience in management and operations associated with reactor and other DOE facilities.

Mr. Bowen has been a qualified operator on US Nuclear Submarines and the Advanced Test Reactor (ATR). He has held numerous management positions at DOE facilities including ATR Shift Supervisor, ATR Critical Facility (ATRC) Reactor Manager, TRA Program Administrator for Document and Record Control, TAN-679 Complex Operations Department Manager, Accelerated Retrieval Project Shift Operations Manager, Site -Wide INL Facility Manager, Work Management System Leader, HFEF Facility Manager, FCF Facility Manager, Spent Fuels/Treatment Facility (SFTF) Manager, MFC Quality Assurance Manager and MFC Training and Performance Assurance Manager.

Mr. Bowen has a Bachelor of University Studies degree with and emphasis in Nuclear Facility Management from Idaho State University and a Masters of Public Administration degree from Idaho State University.

Mr. Bowen has attended Management \& Independent Assessment training provided by JE-T-S Quality Consultants as well as BBWI required training for assessors. Additionally, he is a qualified Nuclear Facility Manager. He was responsible for the development and implementation of company operations policies and procedures supporting the site wide integration of Integrated Safety Management at the INEEL and INL. He has been a key member of successful implementations of safety basis at the ATR, ATRC, Specific 
Manufacturing Capability, RSWF and FCF. He was the Management System Leader for the INL Work Management System and was responsible for the development of the process.

Mr. Bowen helped develop the Startup Notification Report, Plan of Action, and Management Self-Assessment to verify readiness to restart operations for the Contractor Expanded Review for the ATR Technical Safety Requirements and Upgraded Safety Analysis Report Implementation, TAN-679A startup at SMC, and the three startups of Nuclear Facilities as the SFTF NFM.

\subsection{Shannon Corrigan Bio}

Mr. Corrigan is currently the Configuration Management Engineer at MFC. He led the development of the Master Equipment List (MEL) at MFC which combined components into a single list for the MFC facilities. He currently maintains the MFC MEL which is extensively used by the Operations, Maintenance and Engineering organizations. He has over 25 years of experience in engineering and operation of nuclear and waste management facilities. From 1990 to 1993 he was an Experimental Power Reactor Operator at the ATR, holding certifications as reactor console operator and experiment operator. In the fall of 1993, Mr. Corrigan became a System Engineer at the Waste Reduction Operations Complex supporting operations and maintenance of the Hazardous Waste and Mixed Waste Storage Facilities. In 1995, the Waste Experimental Reduction Facility (WERF) was restarted and he became the System Engineer for the WERF's hazardous/low-level radioactive waste controlled air incinerator. This position required specific knowledge of various mechanical systems and plant instrumentation that controlled and monitored incinerator operation. In 2001, the incinerator was shutdown and a Resource Conservation and Recovery Act (RCRA) closure was performed on the facility. RCRA closures were performed by the INL's D\&D organization and as a result, Mr. Corrigan became the on-site D\&D engineer for RCRA closures on the WERF Incinerator, the Sort, Size and Segregation Unit, Stabilization Unit, WROC Storage Units and Repackaging Room. In this capacity, he developed D\&D plans, was the technical point of contact in the field and coordinated all field sampling efforts associated with RCRA closures to ensure clean closure criteria was achieved. In 2004 the RCRA closures were completed and Mr. Corrigan was assigned as the System Engineer for D\&D of Power Burst Facility (PBF) and Experimental Test Reactor (ETR). In this role, he implemented designs for deactivation and decommissioning of ETR and PBF reactor buildings and provided technical direction to operations, planners and project personnel. He worked directly with the applicable facility engineering groups during modifications to active systems to maintain accuracy of facility procedures and drawings. In 2006, Mr. Corrigan transferred from the D\&D organization to ATR Programs Engineering to be a System Engineer during installation and initial startup for the Hydraulic Shuttle Irradiation System. In 2010, he became the Configuration Control Coordinator and point of contact for Design Control issues for ATR Programs Engineering department.

Mr. Corrigan has participated in six readiness reviews while working for the D\&D organization and ATR Programs at the INL.

\subsection{Eric Papaioannou Bio}

Mr. Papaioannou is the Operations Director for the INL Materials and Fuels Complex. He has a total of twenty-nine years of nuclear experience and has worked at MFC for 17 years. He started his nuclear career in the United States Naval Nuclear Program where he spent just over nine years. He was stationed aboard the USS Abraham Lincoln (CVN-72) and at the A1W Prototype as a staff instructor. Following his naval service he entered Idaho State University where he graduated with a B.S. in Physics with an emphasis in radiological engineering. While at ISU he was employed by the Technical Safety Office - 
Radiological Controls group and was responsible for ensuring compliant implementation of the university's NRC broad scope license within all campus research labs.

In 1998 Mr. Papaioannou was hired at Argonne National Laboratory-West as an operator in the Fuel Conditioning Facility. Within three years he became the plant criticality safety engineer eventually picking up responsibilities for multiple MFC facilities. Following the laboratory merger in 2005, he transferred to the Hot Cell Services Department Manager's staff where he qualified as Nuclear Facility Manager for all of the hot cell facilities. In 2006 he became the assistant nuclear facility manager of the Hot Fuel Examination Facility (HFEF) and in 2008 the NFM for the Fuel Conditioning Facility. In mid2009 he was transferred to HFEF to take the NFM role. At the end of 2009 he was given a directed reassignment and became the Operations Department Manager where he stayed until the beginning of FY '14. For the past 17 months he has been on a rotational assignment to the position of MFC Maintenance Department Manager.

Mr. Papaioannou has participated in and led several readiness assessments at MFC including startup of the Material Security and Consolidation Complex (CPP-651), Fresh Fuels Glovebox (AL), Sandia Canister Dismantlement Process (ZPPR), Neptunium Container Storage (FMF), and Advanced Fuel Cycle Initiative Glovebox Startup.

\subsection{Qualifications/Conflict of Interest}

The Team Lead has reviewed the qualifications of the team members and has determined that they meet the following requirements:

- They possess technical knowledge of the core requirements assigned for evaluation and have experience in these areas;

- They have knowledge of performance-based assessment processes and methods; and

- They have knowledge of the facility, activity, or operation specific information sufficient to perform the review of their assigned core requirements.

- The team lead and members have not reviewed work for which they were directly responsible. However, in the area of Training, Mr. Bowen was required to review two items that he was directly involved with. For the two items mentioned, the team lead reviewed the work to maintain independence. The team lead certifies that the other than what has been disclosed, team members are free from a conflict of interest in the areas they were assigned and the review is independent.

\section{APPENDIX A CRA Report Forms (FRM-1469D)}

